\title{
RETÓRICA Y ANÁLISIS DE DISCURSOS
}

\section{Milton José Pinto}

Escola de Comunicação - Universidade Federal do Rio de Janeiro

Enseñada como disciplina obligatoria en escuelas y universidades occidentales hasta el siglo XVIII y tras volver hoy al orden del día, la causa de su presencia en los eventos de los medios, la retórica dejó trazos muy fuertes en nuestra cultura de producción de textos. Surgió en las colonias griegas de Sicilia, allá por el año 485 A.C., se desarrolló, a partir de los procesos de convencimiento utilizados por los hombres en su vida cotidiana, como un conjunto de técnicas para creación de discursos (siempre que se trate de retórica clásica, esta palabra está empleada en el sentido de textos proferidos en vivo delante del público) judiciales, usados en tribunales, en los que se reivindicaba la posesión de tierras. Después estas técnicas salieron de los tribunales hacia otros géneros de textos, frecuentes en la vida cotidiana de los griegos, en los que se argumentaba para defender una tesis: los discursos políticos de las asambleas y los discursos de homenaje. En el transcurso de los siglos, la retórica impregnó también la producción de cualquier tipo de textos, independientemente de los canales movilizados en los procesos de comunicación o del grado de formalidad exigido. Algunas partes de la técnica retórica aún continúan siendo enseñadas hasta hoy como parte 
del programa de otras disciplinas escolares relacionadas con la enseñanza de la redacción, la técnica literaria y la oratoria. Por ser una técnica de producción textual, la retórica es también, de modo más o menos implícito, la primera teoría de la producción y recepción de textos. Sus primeros profesores fueron Empédocles de Agrigento, Corax y Tisias. Roland Barthes (1970: 173) resalta su papel como práctica social que atraviesa los tiempos: «la retórica es esta técnica privilegiada (ya que es necesario pagar para adquirirla) que permite a las clases dirigentes asegurar para sí la propiedad del habla» (el subrayado es del propio Barthes). Algunos especialistas (Declercq, 1992: 20-21) destacan el hecho de que, en su propio origen, la retórica transpone la violencia al campo social y cultural, trasladando la solución de los litigios del ejercicio puro y simple del esfuerzo físico al universo polémico de los discursos. El análisis de discursos, que se interesa particularmente por la disputa de la hegemonía del habla en la sociedad, no deja de ser, de cierta forma, una reflexión sobre la teoría y la técnica de la retórica como práctica social.

El análisis de discursos es una práctica analítica de productos culturales empíricos - denominados textos- que, valiéndose de las teorías desarrolladas por la lingüística y por la semiología sobre el uso del lenguaje y otras semióticas en los procesos de comunicación, busca mostrar, a la luz de las modernas teorías sociales, cómo y por qué tales productos producen ciertos efectos de sentido, obedeciendo a determinadas reglas, convenciones o normas socioculturales (muchas veces tácitas o no explicitadas), intentando modificarlas creativamente. Discurso es definido como práctica social de producción de textos, y en su análisis habrá que tener en cuenta tres niveles de contextualización: lo situacional inmediato, lo institucional y lo social más amplio (Pinto, 1999). La convivencia del análisis lingüístico y semiológico con las teorías de las ciencias sociales y humanas está lejos de ser tranquila, especialmente para los científicos sociales, pero muchos de ellos ya comenzaron a darse cuenta de que alteraciones del uso del lenguaje son parte importante en los procesos de cambio social y cultural más amplios, y esta tendencia está en crecimiento. Inicialmente, dentro de las teorías marcadas por el marxismo, Bakhtin $(1970,1977)$, que tenía a la retórica antigua como un importante punto de referencia, desarrolló la idea de la comunicación como un campo en el que se conquistan posiciones de poder por el ejercicio del lenguaje, anticipando posiciones de Foucault (1971, 1975, 1979). Gramsci (1971) y Althuser (1974) resaltaron la importancia de la ideología en los procesos de reproducción social y Pêcheux (1969) y sus colaboradores, al crear el llamado 
del programa de otras disciplinas escolares relacionadas con la enseñanza de la redacción, la técnica literaria y la oratoria. Por ser una técnica de producción textual, la retórica es también, de modo más o menos implícito, la primera teoría de la producción y recepción de textos. Sus primeros profesores fueron Empédocles de Agrigento, Corax y Tisias. Roland Barthes (1970: 173) resalta su papel como práctica social que atraviesa los tiempos: «la retórica es esta técnica privilegiada (ya que es necesario pagar para adquirirla) que permite a las clases dirigentes asegurar para sí la propiedad del habla» (el subrayado es del propio Barthes). Algunos especialistas (Declercq, 1992: 20-21) destacan el hecho de que, en su propio origen, la retórica transpone la violencia al campo social y cultural, trasladando la solución de los litigios del ejercicio puro y simple del esfuerzo físico al universo polémico de los discursos. El análisis de discursos, que se interesa particularmente por la disputa de la hegemonía del habla en la sociedad, no deja de ser, de cierta forma, una reflexión sobre la teoría y la técnica de la retórica como práctica social.

El análisis de discursos es una práctica analítica de productos culturales empíricos — denominados textos-que, valiéndose de las teorías desarrolladas por la linguística y por la semiología sobre el uso del lenguaje y otras semióticas en los procesos de comunicación, busca mostrar, a la luz de las modernas teorías sociales, cómo y por qué tales productos producen ciertos efectos de sentido, obedeciendo a determinadas reglas, convenciones o normas socioculturales (muchas veces tácitas o no explicitadas), intentando modificarlas creativamente. Discurso es definido como práctica social de producción de textos, y en su análisis habrá que tener en cuenta tres niveles de contextualización: lo situacional inmediato, lo institucional y lo social más amplio (Pinto, 1999). La convivencia del análisis lingüístico y semiológico con las teorías de las ciencias sociales y humanas está lejos de ser tranquila, especialmente para los científicos sociales, pero muchos de ellos ya comenzaron a darse cuenta de que alteraciones del uso del lenguaje son parte importante en los procesos de cambio social y cultural más amplios, y esta tendencia está en crecimiento. Inicialmente, dentro de las teorías marcadas por el marxismo, Bakhtin (1970, 1977), que tenía a la retórica antigua como un importante punto de referencia, desarrolló la idea de la comunicación como un campo en el que se conquistan posiciones de poder por el ejercicio del lenguaje, anticipando posiciones de Foucault (1971, 1975, 1979). Gramsci (1971) y Althuser (1974) resaltaron la importancia de la ideología en los procesos de reproducción social y Pêcheux (1969) y sus colaboradores, al crear el llamado 
análisis automático del discurso, identificaron los discursos como una destacada forma lingüística y material de ideología. Bourdieu (1982), a pesar de sus críticas al análisis de discursos y a su pretensión de partir de datos del análisis lingüístico para explicar fenómenos sociales, incorpora a sus teorías sobre la constitución de los campos sociales y culturales elementos de la pragmática lingüística. Habermas (1984, 1989) también incorpora elementos de la pragmática, al mismo tiempo que enfatiza la colonización de la vida cotidiana por los «sistemas» de la economía y del Estado, lo que él ve como un movimiento de los usos «comunicativos» del lenguaje —orientados para la producción del entendimiento- para usos «estratégicos» del mismo —orientados para volver exitosos los intentos de llevar a las personas a hacer cosas-. El uso estratégico del lenguaje es la esencia de la retórica, cuya difusión, por lo menos desde los tiempos de los griegos, parece invalidar la propuesta de Habermas, según la cual esta «colonización» resulta de un proceso reciente. ¿Será que alguna vez existió un uso puramente «comunicativo» del lenguaje? Para el análisis de discursos contemporáneos tal uso sería una utopía, cuya concepción parece haber sido heredada por Habermas de la pragmática lingüística.

Aunque los abordajes generalistas tradicionales aún sean predominantes, el lingüista y analista de discursos Norman Fairclough (1992) trata de mostrar que el creciente interés de científicos sociales por los usos del lenguaje podría estar ligado a un real aumento de la importancia de la función del lenguaje en los procesos sociales. Da como ejemplos probatorios de su hipótesis la extensión de la noción de mercado a nuevas áreas de la vida social: como la educación, sentida principalmente en las modificaciones sufridas por las prácticas discursivas, es decir, por las prácticas de lenguaje (relexicalización de actividades y relaciones: por ejemplo, nombrando a los alumnos como «consumidores» o «clientes», cursos como «paquetes», y una sutil reestructuración de las prácticas discursivas de la escuela, bajo el impacto de discursos venidos del exterior, como los de la publicidad, la administración y la consejería); la transformación de la cultura discursiva en los locales de trabajo de muchas empresas, con la creación de los «círculos de calidad», que dan más voz a los empleados con relación a la administración; y cambios en las relaciones entre médicos y pacientes, entre los políticos y el público, entre hombres y mujeres en los locales de trabajo, por la alteración de prácticas discursivas vigentes hasta hace poco.

La creciente importancia dada a las prácticas discursivas en las transformaciones sociales viene sumándose a una preocupación de su 
control por medio de tecnologías discursivas de poder, aplicadas por profesionales que, sistemáticamente, investigan, proyectan y aplican entrenamientos en prácticas discursivas, como los psicólogos sociales involucrados en skill training (Argyle, 1978). El análisis de la naturaleza del poder en las sociedades modernas, desarrollado por Foucault en algunos de sus trabajos de la fase genealógica (Foucault, op. cit.), colocó el discurso y el lenguaje en el ámbito de los procesos y prácticas sociales. El carácter del poder en las sociedades modernas aparece unido al problema de administrar las poblaciones. El poder está implícito en las prácticas sociales del día a día y distribuido en todos los dominios de la vida social, en la cual está permanentemente involucrado, sin mostrarse abiertamente. El poder moderno no es impuesto desde arriba por ningún agente colectivo, como una clase social o el Estado, sobre grupos o individuos; él se desarrolla «desde abajo» por medio de ciertas «microtécnicas», como el examen, en los sentidos médico y escolar, que surgió en instituciones hospitalarias, prisiones y escuelas en el inicio del período moderno. Estas técnicas de poder se desarrollaron teniendo como base los conocimientos generados, por ejemplo, por las ciencias humanas y sociales; mas por otro lado, estas técnicas son empleadas, con gran frecuencia, para ejercer el poder en la captación del saber. El poder y el saber están así en una relación binaria de implicación en la sociedad moderna. Algunas de esas tecnologías discursivas de poder están en las manos de profesionales de la comunicación, como periodistas y mercadólogos, que las aprendieron en las facultades o redacciones bajo el inocente disfraz de una técnica sin ideología, independiente de los contextos sociales, como habilidades que pueden ser aplicadas en diferentes y variados dominios culturales. Algunos ejemplos son las técnicas de redacción periodística (el encabezado y la pirámide de información invertida; la selección, la valorización y la jerarquización, por parte del periodista, de las noticias, según el impacto afectivo-emocional que pueden causar en el público), introducidas en los periódicos brasileños a partir de los años 50 y las técnicas publicitarias. Volviéndose hegemónicas, dejaron de ser percibidas como motivadas socialmente y se transformaron en recetas de aplicación obligatoria y generalizada, objeto de enseñanza reverenciada y defendida ardorosamente por sus practicantes (periodistas, publicistas y profesores), temerosos de perder su pequeña parcela de poder/ saber. En la constitución de estas técnicas, un componente importante y privilegiado es la retórica clásica.

La práctica retórica llegó a su apogeo, dentro de la cultura griega, con los sofistas, como Gorgias y Protágoras, que fueron duramente 
atacados por Platón, por la boca de su filósofo-personaje Sócrates, en diversos de sus diálogos más polémicos y tendenciosos (Fedro, Gorgias, Protágoras, Teeteto, Sofista), por sustituir la búsqueda del conocimiento y de la verdad por la construcción de simulacros verosímiles que escondían intereses de individuos y grupos, utilizando una técnica de producción discursiva, centrada más en la emoción que en la razón, destinada a la cooptación del público. El primero de esos intereses estaría unido, en la crítica del Sócrates platoniano, al hecho de que los sofistas recibían dinero para preparar o enseñar cómo preparar discursos, tal como los profesionales de comunicación de hoy, profesores o especialistas de los medios. Entonces, esta concepción de discurso como simulacro interesado (que Aristóteles dejó en segundo plano en su Arte Retórica por las críticas de Platón, que renació a partir de Roma y de las obras de Cicerón) es uno de los conceptos centrales del análisis de discursos contemporáneos. Platón, evidentemente, como la mayoría de las personas, especialmente intelectuales y políticos de todas las épocas, de modo dogmático y autoritario, pensaba sinceramente que sus propios discursos no eran simulacros en el sentido que criticaba y sí la expresión de la verdad. Fue una víctima ilustre de ceguera ideológica. Aristóteles fue más cuidadoso: en lugar de oponer verosimilitud y verdad, como su maestro, prefirió concentrarse en la definición de los buenos y malos usos de la retórica, como un arte de la verosimilitud al servicio de la argumentación en los discursos de la vida práctica. Intentó en este sentido establecer una diferenciación entre verosimilitud absoluta y verosimilitud aparente, por ejemplo, al criticar técnicas argumentativas de Corax y Protágoras (Aristóteles, Arte Retórica, II, 24):

Son aplicaciones de ese lugar que componen la techné de Corax: si un hombre no da margen a que a él sea dirigida una acusación, si, por ejemplo, un hombre físicamente débil es acusado de agresión, su defensa será que no sería verosímil ser culpable; mas si el acusado da margen a la acusación, si, por ejemplo, él es físicamente fuerte, su defensa será que no sería verosímil que él fuera culpable, ya que sería verosímil que se creyera que él es culpable. Lo mismo sucede en otros casos; pues necesariamente, o se da o no se da margen a la acusación; entonces, los dos casos parecen verosímiles; mas uno es realmente verosímil; el otro no es verosímil de forma absoluta, mas en la medida de lo que acabamos de decir y tornar el más débil de los argumentos en el más fuerte consiste precisamente en eso. Así nos indignaríamos con razón de la profesión de Protágoras; pues es una carnada, una apariencia de verosimilitud.

Tanto a Platón como a Aristóteles les faltaba la percepción, que hoy forma parte del día a día del análisis de discursos, de que verdad y 
verosimilitud no son valores absolutos, sino valores sociales que los interlocutores deben conquistar en los embates comunicacionales. Todo proceso de comunicación es un proceso polémico de convencimiento, donde poder y saber están en juego y donde los valores sociales se reproducen o se modifican. La práctica discursiva es, dialécticamente, al mismo tiempo constitutiva y creativa (v. Fairclough, pássim) de aquellos valores.

La retórica, según Aristóteles (op. cit.) y Cicerón (1964, 1973), es el arte (palabra que en el sentido clásico es más o menos equivalente en sentido a lo que hoy denominamos técnica) de persuadir relativamente las causas comunes bajo el ángulo de lo justo y de lo injusto, de lo útil o de lo perjudicial, del bien y del mal lo que lleva a la definición de tres géneros de discursos, respectivamente: el judicial, el deliberativo y el epidíctico (demostrativo o teórico). Los tratados de retórica dividían tradicionalmente la producción de un discurso en cinco fases: la invención o creación de los lugares de argumentación (topoi); la disposición o agenciamiento estructurado de las pruebas a lo largo del texto; la elocución o elección de las palabras y expresiones - uso de las llamadas figuras de la retórica, en las que se incluyen las figuras de sustitución o tropoi, como la metáfora - apropiadas para la finalidad del discurso; la memoria o técnica de memorización del discurso, preparatoria para su realización oral en público; y la acción o técnica para la realización física del discurso (uso de la voz y de la expresión corporal), como en una representación teatral. Las dos últimas partes prácticamente fueron olvidadas por los tratados a partir de la Edad Media, aunque se mantuvieron en la tradición por un proceso de imitación. Voy a resumir y comentar, siempre desde el punto de vista del análisis de discursos contemporáneos, la segunda $\mathrm{y}$, principalmente, la primera de las partes de la retórica.

La invención, primera etapa de la preparación de un discurso según la techné rhetoriké, no tiene nada de invención, en la acepción de la palabra. Los argumentos para usar en un determinado discurso son copiados de discursos anteriores de la tradición, donde habían funcionado bien, por lo que se acostumbraba a reunirlos en listas y clasificarlos en relación al tipo de público al que deberían ser aplicados, a disposición de los interesados, como en la Tópica de Aristóteles. La idea de polifonía, tan presente en los análisis actuales por la influencia de Mijail Bajtín (op. cit.), encuentra ahí su fundamento. Los lugares de argumentación o topoi eran organizados en tres pruebas (o deberes del orador según Cicerón): la prueba ética, relativa a la imagen 
que el orador muestra de sí mismo en su discurso (el orador debe agradar) la prueba patética, relativa a las pasiones que se deben despertar en la audiencia (el orador debe conmover) y la prueba lógica, relativa a los razonamientos en que los argumentos eran empleados (el orador debe instruir).

La prueba ética (Aristóteles, Arte Retórica, II, 1) consistía en crear con el discurso un ethos, carácter o imagen moral del orador y el efecto de esta imagen sobre el público, cuya disposición buena o mala determina la eficacia del discurso. Como el arte retórico argumenta dentro del sentido común, con miras a la creación de verosimilitud, el crédito del orador ante el público es un factor decisivo, pues la confianza del público abre el camino para la persuasión. El concepto de ethos se modificó por influencia de la tradición cristiana en un sentido moralizante, siendo muchas veces interpretado con el sentido de que el valor moral del orador es lo que determina el éxito del discurso y garantiza su honestidad. Declerq (1992: 47) muestra que esta interpretación es totalmente ajena al pensamiento aristotélico: se persuade por el carácter cuando el discurso en sí mismo torna al orador digno de fe. El ethos debe ser comprendido como una condición técnica e intrínseca del proceso de persuasión, y no como cualidades morales extrínsecas al orador. El arte de argumentar es amoral y sólo su uso puede ser regido, externamente, por la moral vigente. Era común en los exámenes de retórica en la Edad Media que el alumno tuviera que presentar ante la banca examinadora dos discursos: uno atacando, otro defendiendo la misma tesis; como ya se dijo, como tecnología discursiva de conquista de hegemonía, la retórica es considerada ideológicamente neutra. Verdad, verosimilitud, valores éticos o estéticos quedan a juicio del público, en la recepción. La prueba ética define el discurso como un espectáculo, afectando duramente cualquier ilusión de sinceridad. Es importante también registrar que, para Aristóteles, esta imagen del orador es también distinta del contenido del discurso: no se trata de un autorretrato benévolo y elogioso. El ethos es exactamente lo que el análisis de discursos denomina hoy sujeto de la enunciación o enunciador (Pinto, 1999: 31): la actividad discursiva deja un conjunto de marcas formales que remiten a la persona del orador, con miras al público. La memoria sociocultural de éste se encarga, casi instintivamente, de identificar e interpretar cada una de los marcas como un indicio, a medida que el discurso es proferido. La prueba ética se constituye así por todo lo que en el proferimiento del discurso contribuye a crear una imagen del orador destinada al público: tono de voz, velocidad de emisión del habla, elección de 
modos de decir (palabras, tipos de frases, argumentos, etc.) y de modos de mostrarse (gestos, mímica, dirección de la mirada, postura, ropas, adornos, etc.); todo aquello que el orador moviliza para hacer una imagen psicosociológica de sí mismo. Nuestros mercadólogos políticos no inventaron nada.

La prueba patética (Aristóteles, Arte Retórica, II, 1-17) consistía en provocar en el público un pathos o una pasión, con el objetivo de tornar más favorable su disposición para juzgar. La movilización de la pasión del público era conseguida a través de una representación de comportamientos, acciones o situaciones susceptibles de inducirlas. En la definición aristotélica, la palabra pasión se aleja de su sentido etimológico (asociado a sufrimiento moral) y pasa a ser entendida en el proceso de persuasión como agente de variación del juicio: «Las pasiones son las causas que hacen variar a los hombres en sus juicios y tienen como consecuencia el dolor o el placer, como la cólera, la piedad, el miedo, y todas las otras emociones de ese género, así como sus opuestos» (op. cit., II, 1). Aristóteles analiza las pasiones por grupos de contrarios, como sugieren las citas: cólera y calma (II, 2 y 3); amistad y odio (II, 4); miedo y seguridad (II, 5); verguienza e impudor (II, 6); dedicación y descuido (II, 7); piedad e indignación (II, 8 y 9); envidia y desprecio (II, 10 y 11). A estas definiciones agrega la de los caracteres según la edad (juventud/vejez/madurez - II, 12, 13 y 14); las de nobleza y generosidad (II, 14) y las de los ricos y los poderosos (II, 17). La prueba patética exige por parte del orador un saber psicosocial sobre las pasiones, relativo a tres puntos que Aristóteles en sus definiciones tomó prestados de Platón del Fedro: qué disposición emocional previa (habitus) es favorable al surgimiento de la pasión; a quién está dirigida; y relativamente a qué objetos. Este conocimiento suministra las premisas del razonamiento persuasivo y define una doxa o sentido común compartido por el orador y su público, donde los valores ideológicos hegemónicos están cristalizados. El pathos sería lo que en el análisis de discursos contemporáneos se denomina sujeto hablado o destinatario (Pinto, 1999: 31), el lugar o imagen que el orador crea en su discurso para que ocupe el público. Los argumentos éticos y patéticos, que se destinan a capturar la aprobación del público por el lado emocional, creando imágenes simpáticas y empáticas del orador y de su público, respectivamente, en el interior de los textos, son hoy llamados por los analistas efectos de sentido.

La prueba lógica (Aristóteles, Arte Retórica, I, 4-15 y II, 18-26), que en relación a las dos pruebas anteriormente comentadas generalmente 
se rotula como prueba objetiva, consistía en el propio discurso, en aquello que demuestra o parece demostrar. Define la argumentación racional por la capacidad persuasiva interna del lenguaje y recibe de Aristóteles, que respondía a las críticas de Platón, como se mencionó anteriormente, una atención y un desarrollo que otros tratados de retórica no tenían. Por lo tanto, la prueba lógica se referiría al enunciado, a la estructura del razonamiento y no a la enunciación, como las pruebas ética y patética, y trae a los estudios de lenguaje un método de argumentación discursiva. Aristóteles intenta desarrollar una lógica apropiada a la persuasión, al mundo de la verosimilitud, partiendo de conceptos que desarrolló en otros textos, como los de inducción y deducción y el cálculo silogístico. El razonamiento inductivo básico es llamado ejemplo. La prueba lógica usa diversos tipos de ejemplos: el imago consiste en citar a alguien conocido del público como ejemplo de determinados atributos o comportamientos y ganó vida propia como un género literario: el retrato. Aparece hoy a toda hora en anuncios publicitarios, donde figuras notorias de la cultura son asociadas a un producto ( $\mathrm{vg}$. Pelé anunciando vitaminas o pilas; la actriz Tonia Carrero vendiendo productos de belleza). Otros dos tipos de ejemplos, de carácter narrativo, ganaron también vida propia como géneros literarios (la parábola y la fábula), y ganaron igualmente lugar de destaque en los anuncios contemporáneos, especialmente en clips para televisión. Aparecen también en secciones de periódicos y revistas donde son presentadas diversas pequeñas narrativas (faits divers), curiosas o ejemplares, de hechos de la actualidad, como en la sección «A Semana» de la revista semanal $I$ sto $E$. Son narrativas que ejemplifican comportamientos y atributos buenos o malos, y se distinguen por la extensión (la parábola generalmente es extremamente corta, unas dos o tres frases apenas) y por la manera de representar los comportamientos retratados (la fábula sucede en la mayoría de las veces entre animales que hablan y que se comportan como seres humanos). Una característica importante de los ejemplos retóricos es que las historias y personajes raramente son sacados de lo cotidiano, sino de la mitología, la Biblia y obras literarias, e incluso cuando lo son, como en los ejemplos de las secciones de faits divers o en los anuncios con personalidades anteriormente citados, lo que se muestra es la figura pública de las personas mencionadas, tipificadas y transformadas en personajes de las narrativas mediáticas.

El razonamiento deductivo básico es denominado entimema, que es una forma derivada del silogismo, en el que la premisa mayor genérica en lugar de ser necesaria es apenas probable o incluso apenas posible. 
Con frecuencia, los entimemas no aparecen completos en el texto, quedando registradas apenas una de las premisas o la conclusión, dejando al público la tarea de completar el razonamiento. Un uso común de los entimemas en textos periodísticos aparece en noticias en las que el periódico no quiere o no puede afirmar nada con todas las letras. En el noticiario sobre el reciente asesinato de un diplomático en Curitiba, Paraná, los periódicos se esmeraron en presentar a la víctima como un hombre que vivía solo, no recibía visitas de mujeres y era visto en casas nocturnas acompañado de muchachos, definiendo una premisa menor de entimema y dejando al público la tarea de deducir la conclusión: la víctima era homosexual. Gran parte de los slogans publicitarios son entimemas o parte de entimemas. En un anuncio reciente aparece un buen ejemplo de entimema retórico: un fabricante de automóviles argumenta con el slogan: «Un gran carro no necesita necesariamente ser un carro grande», destacado en texto perforado sobre fondo azul oscuro. En el inicio del texto a la izquierda de este slogan, también perforado sobre el fondo azul oscuro, pero en tipos menores, aparecen como un título las frases: «Nuevo Renault Clio» y, justo en la línea de abajo, «Llegó el pequeño gran carro brasileño». Se trata de un entimema completo, pues tiene presentes las dos premisas y la conclusión, y se enriquece retóricamente con el uso del quiasmo («gran carro»/«carro grande»); con el doble sentido del adjetivo «grande», al funcionar como explicativo al ser antepuesto al sustantivo y como restrictivo, al ser pospuesto; y por el uso del oximoron («pequeño gran carro») en la conclusión. La imagen que sirve de fondo al anuncio reduplica la conclusión, mostrando un ejemplar del modelo de carro en cuestión estacionado, en frente de un gran edificio con el frente de vidrio, donde el vehículo se refleja agigantado. Se ve que la prueba lógica está lejos de ser un razonamiento correcto; es incluso un razonamiento falso la mayoría de las veces, según las leyes de la verdadera lógica, reforzando el carácter de simulacro de los discursos. En realidad, su principal función no me parece que sea argumentar, de hecho, sino mostrar al orador como alguien que sabe razonar con sentido común. A pesar de ser presentada como una prueba objetiva, es más un trazo que remite al ethos del orador y a la enunciación.

La segunda etapa de la producción de un discurso, dentro de la técnica de la retórica, es la disposición, que consiste en la organización del texto en partes y subpartes, cada una con una función específica. El modelo que conocimos de este capítulo de la retórica, en el que el discurso se divide en cuatro partes, nos llegó a través de la obra de 
Cicerón, titulada Particiones Oratorias (Declercq, 1992: 157): exordio, narración, prueba y peroración. El exordio consiste en un vocativo inicial para captar la benevolencia del público (simpatía, interés y atención), con miras a movilizar al mismo tiempo las pruebas éticas y patéticas; y en la presentación de la causa que tratará y de la tesis del orador sobre ella. La narración, que también se volvió un género literario independiente, consiste en la exposición de los hechos sobre los cuales el orador se apoya para establecer la convicción. Se trata de la parte central de la disposición, donde el orador organiza estratégicamente los elementos de verosimilitud - pruebas, índices o creencias, destinados a convencer al público, sacando partido de las virtudes explicativas de la narrativa. El ethos es igualmente solicitado, pues la credibilidad de la narrativa explicativa está ligada a la imagen del orador. No es otro el papel de la «objetividad» que los periodistas trajeron al día a día de los periódicos al introducir las técnicas del encabezado y de la pirámide invertida como regla básica del género narrativo noticia. La prueba se dividía en confirmación, que reúne las pruebas del orador, y en refutación, con la que el orador busca destruir las pruebas del adversario. En ambas partes el orador hace una amplia apelación a la llamada prueba lógica, comentada anteriormente, además de utilizar procedimientos comunes en textos literarios, como analogía, descripción, enumeración o explicación por la etimología. La idea de dialogismo, muy presente en los análisis contemporáneos gracias a la teorización bajtiniana, aparece aquí claramente: dos visiones o tesis contradictorias, que Foucault (op. cit.) denomina discursos, en su fase genealógica, se enfrentan en el ámbito discursivo. La peroración amplifica y resume la causa o tema, con miras a despertar las pasiones del público a través del uso de las figuras retóricas de la elocución: metáforas, acumulación, graduación, prosopopeya. Los discursos persuasivos contemporáneos conservan también mucho de esta estructura básica, aunque hayan sido creadas diversas variantes en las que la presencia, el peso y el orden de las partes puedan ser alterados ( $\mathrm{v}$. Pinto, 1997). El carácter eminentemente literario de la estructura y de los ornamentos sirve aquí también como argumento ético. Al movilizar esos recursos, el orador demuestra su pertenencia a una cultura compartida con el público y revela destreza en un tipo de texto altamente prestigiado en Occidente. En el ámbito discursivo, la hegemonía es conquistada principalmente por el uso del ethos y, en menor escala, por el del pathos, es decir, la eficacia persuasiva de los discursos está más unida a su enunciación (sus modos de mostrar, interactuar, seducir) que al enunciado (lo que es dicho, su contenido). 


\section{Referencias bibliográficas}

ALTHUSER, L. (1974). Ideologia e aparelhos ideológicos do Estado. Lisboa: Presença/Martins Fontes.

Argyle, M. (1978). The Psychology of Interpersonal Behaviour (3. ${ }^{\mathrm{a}}$ ed.). Harmondsworth: Penguin Books.

ARISTÓTELes (1981). Arte retórica e Arte poética. Rio de Janeiro: Ediouro.

BakHtin, M. (1970). Problèmes de la poétique de Dostoievski. Lausanne:

L'Âge d'Homme.

- (1977). Le marxisme et la philosophie du langage. Paris: Minuit.

BARTHES, R. (1970). «L'ancienne rhétorique». Communications 16, 172-227.

BOURDIEU, P. (1982). Ce que parler veut dire: L'économie des échanges linguistiques. Paris: Fayard.

CiCERÓN, M. T. (1964). L'orateur (Ed. LA. Yon). Paris: Les Belles Lettres. - (1973) Brutus (Ed. J. Martha). Paris: Les Belles Lettres.

DECLERCQ, G. (1992). L'art d'argumenter-Structures rhétoriques et littéraires. Paris: Éditions Universitaires.

FAIRCLOUgH, N. (1989). Language and Power. Harlow: Longman.

- (1992). Discourse and Social Change. Cambridge: Polity Pres.

FouCAULT, M. (1971). L'ordre du discours. Paris: Gallimard.

- (1975). Surveiller et punir. Paris: Gallimard.

- (1979) Microfísica do poder. Rio de Janeiro: Graal.

GramsCI, A. (1971). Selections from the Prison Notebooks (Ed. y trad. Q. Hoare \& G. Nowell Smith). Londres: Lawrence and Wishart.

HABERMAS, J. (1984). The Theory of Communicative Action (2 vols.). Londres: Heineman.

- (1989). The Structural Transformation of the Public Sphere. Cambridge: Polity Press.

PÊCHEUX, M. (1969). L'analyse automatique du discours. Paris: Dunod.

PINTO, M. J. (1997). «Receitas de editorial». En Mídia e cultura, A. Fausto

Neto \& M. J. Pinto (ed.), 45-56. Rio de Janeiro, Diadorim/COMPÓS.

- (1999). Comunicação e discurso-Introdução à análise de discursos. São Paulo: Hacker. 